\title{
A multi-analytical approach to gold in Ancient Egypt: Studies on provenance and corrosion
}

\author{
I. Tissot a,b,*, L.G. Troalen ${ }^{c}$, M. Manso ${ }^{\mathrm{a}, \mathrm{d}}$, M. Ponting ${ }^{\mathrm{e}}$, M. Radtke ${ }^{\mathrm{f}}$, U. Reinholz ${ }^{\mathrm{f}}$, M.A. Barreiros ${ }^{\mathrm{g}}$, I. Shaw ${ }^{\mathrm{e}}$, \\ M.L. Carvalho ${ }^{\text {a }}$, M.F. Guerra ${ }^{\mathrm{h}}$ \\ a LIBPhys - UNL, Faculty of Science and Technology, 2829-516 Caparica, Portugal \\ b Department of Physics, Faculty of Sciences, University of Lisbon, Campo Grande, 1649-004 Lisbon, Portugal \\ c National Museums Scotland, Collections Services Department, 242 West Granton Road, Edinburgh EH5 1JA, UK \\ d Faculdade de Belas-Artes da Universidade de Lisboa, Largo da Academia Nacional de Belas-Artes, 1249-058 Lisbon, Portugal \\ e Archaeology, Classics and Egyptology, University of Liverpool, 12-14 Abercromby Square, Liverpool L69 7WZ, UK \\ ${ }^{f}$ BAM Federal Institute for Materials Research and Testing, Richard-Willstaetter-Strasse 11, 12489 Berlin, Germany \\ g LNEG, I.P., Estrada do Paço do Lumiar, 22, 1649-038 Lisbon, Portugal \\ h ArchAm, UMR 8096 CNRS - Université Paris Sorbonne, MAE, 21 allée de l'Université, 92023 Nanterre, France
}

\section{A R T I C L E I N F O}

\section{Article history:}

Received 12 December 2014

Accepted 26 March 2015

Available online 7 April 2015

\section{Keywords:}

Gold

Egypt

PGE

Provenance

Corrosion

\begin{abstract}
A B S T R A C T
Recent results from a three-year multi-disciplinary project on Ancient Egyptian gold jewellery revealed that items of jewellery from the Middle Kingdom to the New Kingdom were manufactured using a variety of alluvial gold alloys. These alloys cover a wide range of colours and the majority contain Platinum Group Elements inclusions. However, in all the gold foils analysed, these inclusions were found to be absent. In this work a selection of gilded wood and leather items and gold foil fragments, all from the excavations by John Garstang at Abydos (primarily from Middle Kingdom graves), were examined using Scanning Electron Microscopy-Energy Disperse Spectroscopy (SEM-EDS), X-Ray Fluorescence ( $\mu \mathrm{XRF}$ ), Particle Induced X-Ray Emission ( $\mu \mathrm{PIXE}$ ) and Double Dispersive X-Ray Fluorescence ( $D^{2} \mathrm{XRF}$ ). The work allowed us to characterise the composition of the base-alloys and also to reveal the presence of Pt at trace levels, confirming the use of alluvial gold deposits. Corrosion products were also investigated in the foils where surface tarnish was visually observed. Results showed that the differences in the colour of corrosion observed for the foils are related not only to the thickness of the corrosion layer but also to a multi-layer structure containing the various corrosion products.
\end{abstract}

C 2015 Elsevier B.V. All rights reserved.

\section{Introduction}

Goldwork from Ancient Egypt was made in a wide variety of colours. The few publications on the analytical study of gold and silver items show the use of a large range of gold base-alloys [1-7] and also the exploitation of gold and aurian silver sources [8,9]. One recent publication showed, however, that during the 2nd Intermediate Period (ca. 1650-1550 BC) a variety of gold colours may be observed within a single tomb and among items belonging to a single individual [5], as is also found in the New Kingdom (ca. 1550-1070 BC) [2]. This reflects the use of different alloying practices or the exploitation of gold from different origins [8].

A primary question is that of the origin of the gold. How could the Egyptian goldsmith achieve such a rich palette of gold shades? Before the introduction of parting in the metallurgical process of gold during the first millennium $\mathrm{BC}$ [1], diverse colours could only be achieved by the exploitation of different sources of gold.

\footnotetext{
* Corresponding author at: Department of Physics, Faculty of Sciences, University of Lisbon, Campo Grande, 1649-004 Lisbon, Portugal. Tel.: + 351939212005.

E-mail address: isabeltissot@gmail.com (I. Tissot).
}

In their publication on the excavations of Naqada and Ballas in 1896, Petrie and Quibell [10] were the first to report the presence of osmiridium inclusions in the 12th Dynasty scarab of Mu-en-ab. The presence of Platinum Group Elements (PGE) inclusions in gold is always related to the use of alluvial sources [11] and the characteristics of the PGE composition have been suggested as a possible indicator for a change of source [12].

Since the publication by Petrie and Quibell in 1896 [10], other authors have referred to the presence of PGE inclusions on the surface of Egyptian goldwork, mentioning their quite heterogeneous compositions $[5,12,13]$. In spite of the discovery of Os-rich and Os-Ir alloy minerals in the Eastern Desert [14], the PGE mineralogy of Egypt remains very poorly documented. Recent publications have remarked on the consistent presence of PGE inclusions on the surface of Egyptian gold jewellery [4,5,15]. With the exception of the recent analysis of gilded wood samples from the tomb of Tutankhamun, which characterised the Pt element in two regions of analysis [16], the presence of PGE inclusions in gold foils from Ancient Egypt has hitherto never been characterised.

Before the presence of PGE elements can be used to demonstrate that the foils were produced using gold from different sources (which may not be alluvial but mined), the experimental difficulties in the 